\title{
Viabilidade de Implantação do Contrato Futuro de Trigo na BM\&FBOVESPA*
}

\section{Feasibility of the Implementation of Future Contract for Wheat in BM\&FBOVESPA}

\author{
Fernanda Schwantes** \\ Leonardo Bornacki de Mattos*** \\ Alexandre Bragança Coelho**** \\ Viviani Silva Lirio*****
}

Resumo: Este trabalho procura avaliar a viabilidade de implantação do contrato futuro de trigo pela BMEJFBOVESPA. Utiliza-se a Teoria do Sucesso e Fracasso de Contratos Futuros como suporte teórico e metodológico para a pesquisa, a qual apresenta características consideradas necessárias à viabilidade de lançamento de um novo contrato futuro e subdivide-se em duas avaliações complementares, denominadas abordagens macro e micro. A primeira busca identificar se o mercado do trigo em grão no Brasil é adequado para se negociar o contrato futuro da commodity, enquanto a segunda avalia o perfil dos agentes da cadeia produtiva do trigo, que são os potenciais usuários desse contrato. Em geral, evidencia-se que o mercado físico do trigo atende a grande parcela dos atributos considerados necessários à implantação de um contrato futuro. No entanto, pesam contra o lançamento desse contrato o tamanho do mercado físico e a intervenção governamental, de modo que o lançamento do contrato futuro de trigo no Brasil é considerado um movimento precipitado.

Palavras-chave: Trigo. Comercialização. Contratos futuros. BMEJFBOVESPA.

Abstract: This study evaluates the feasibility of implementing the wheat futures contract by the Brazilian commodities and futures exchange (BMEFBOVESPA). It use the Theory of Success and Failure of Futures Contracts as theoretical and me-

\footnotetext{
* Os autores agradecem o apoio financeiro da Fapemig e do CNPq para a condução desta pesquisa.

** Professora do curso de Ciências Econômicas da Universidade Federal de Mato Grosso (UFMT). Doutoranda em Economia Aplicada pela Escola Superior de Agricultura Luiz de Queiroz da Universidade de São Paulo (ESALQ|USP). E-mail: fe.schwantes@gmail.com

*** Professor do Departamento de Economia Rural da Universidade Federal de Viçosa (UFV). Bolsista do Programa Funarpex, da Fundação Arthur Bernardes (Funarbe). E-mail: lbmattos@ufv.br

**** Professor do Departamento de Economia Rural da Universidade Federal de Viçosa (UFV). E-mail: acoelho@ufv.br

***** Professora do Departamento de Economia Rural da Universidade Federal de Viçosa (UFV). E-mail: vslirio@ufv.br
} 
thodological support for this research, which presents characteristics considered necessary for the viability of launching a new futures contract. This theory is subdivided into two complementary evaluations, which are called micro approach and macro approach. The first seeks to identify whether the wheat grain market in Brazil is appropriate to negotiate the commodity's futures contract, while the second approach evaluates the profile of agents in the wheat supply chain, which are the potential users of this contract. In general, it is evident that the physical market for wheat meets a large portion of the attributes considered necessary for the establishment of a futures contract. Nonetheless, the small size of the physical market and strong government intervention weigh against the release of this contract, making the launch of the wheat futures contract in Brazil a precipitated movement.

Keywords: Wheat. Commercialization. Futures contracts. BMEFBOVESPA.

JEL Classification: G13; Q14.

\section{1 lntrodução}

O setor tritícola no Brasil, marcado pelo apoio governamental elevado até 1990, que permitia a todos os segmentos da cadeia produtiva do trigo usufruir de uma estrutura estável de compra e venda do trigo nacional e importado, foi exposto a um choque de eficiência com a extinção do monopsônio-monopólio estatal na comercialização da commodity.

Esse fato está diretamente associado às mudanças estruturais do início da década de 1990, ressaltando-se o processo de abertura comercial e de internacionalização da economia brasileira, seguindo os preceitos de economia de livre mercado, a redução gradativa dos impostos sobre importações - que culminou em maior liberdade de compra de produtos estrangeiros -, a retração da atuação do Estado como provedor do financiamento e regulamentador da comercialização agropecuária - devido à crise fiscal da década de 1980 - e a formação do Mercosul a partir de 1991. Esses eventos alteraram a dinâmica de formação dos preços internos do cereal, acentuando as oscilações de preços a que estão suscetíveis os agentes da cadeia produtiva do trigo no país nos diferentes meses do ano.

Além disso, em decorrência das condições de oferta interna, que é extremamente imprevisível em função da sensibilidade da cultura aos flagelos climáticos e aos elevados custos de produção, que impossibilitam a concorrência com o trigo importado, substancialmente subsidiado e de melhor qualidade, e da dependência expressiva por importações, os preços internos apresentam-se bastante voláteis, o que dificulta o planejamento e gerenciamento por parte dos agentes envolvidos na cadeia produtiva do trigo no Brasil. 
Embora o governo federal ainda disponibilize ao setor tritícola instrumentos de financiamento da produção e comercialização, como o Prêmio de Escoamento do Produto (PEP), as Aquisições do Governo Federal (AGF), os Empréstimos do Governo Federal (EGF), a Cédula do Produto Rural (CPR) e o contrato de opção de venda e sua recompra (CAFÉ et al., 2003), esses mecanismos apresentam-se, muitas vezes, como práticas descontínuas e, além disso, garantem apenas a compra do produto ao preço mínimo estipulado nos momentos em que o mercado está atuando abaixo desse valor.

Segundo Brum e Heck (2005), embora o governo tenha divulgado o preço mínimo de comercialização do trigo nos anos subsequentes às mudanças de 1990, dificilmente ele adquire o produto. Em 2003, por exemplo, a produção foi comercializada, em sua maior parte, abaixo do valor oficial do governo, induzindo muitos produtores a exportar o produto, fato que havia ocorrido pela última vez em 1820 (BRUM; HECK, 2005).

Assim, tem-se evidenciado a necessidade de novos instrumentos de análise de eficiência, administração de riscos de preços e alternativas de financiamento e comercialização da produção tritícola. Um mecanismo já utilizado pelo setor triticultor em diversas partes do mundo, especialmente nos Estados Unidos, constitui-se nos mercados futuros. Os mercados futuros oferecem um mecanismo competitivo e eficiente de estabelecimento de preços para as commodities, permitindo a transferência de risco de preços e reduzindo os componentes geradores de distorções mercadológicas, como superoferta e nível de estoques reguladores, além da padronização e homogeneização de produtos (HULL, 2005).

O desenvolvimento e lançamento de um novo contrato junto às bolsas de mercadorias e futuros é um processo dispendioso, tanto financeiramente, quanto em termos de tempo, como salientam Pennings e Leuthold (1999). Assim, como muitos estudos $^{1}$ apontam que a maioria dos contratos falha ${ }^{2}$ em menos de 10 anos a partir da sua introdução, a identificação de fatores determinantes do sucesso ou do fracasso de novos derivativos anteriormente ao seu lançamento torna-se relevante. O estudo de Pennings e Leuthold (1999) propõe que essa análise seja feita sob duas perspectivas, as quais têm sido denominadas, na literatura de mercados futuros, de abordagem macro e abordagem micro. Na abordagem macro, são definidas as características físicas da commodity e do seu mercado, enquanto na abordagem micro, são levantadas as características dos potenciais usuários do contrato e o seu interesse em adotar esse novo contrato futuro.

No Brasil, os contratos futuros são comercializados na Bolsa de Valores, Mercadorias e Futuros (BMEFBOVESPA), sendo que, no mercado de derivativos agro-

\footnotetext{
Ver Brorsen e Fofana (2001).

O fracasso de um contrato futuro relaciona-se ao volume de comércio em um dado período, de forma que um contrato é considerado tão mais bem sucedido quanto maior for seu volume de comércio (AGUIAR, 2003).
} 
pecuários, negociam-se, atualmente, contratos de açúcar cristal, etanol, boi gordo, café arábica, milho e soja. Em termos de mercado internacional, o contrato futuro de trigo é negociado em pelo menos 17 bolsas no mundo, ${ }^{3}$ em todos os continentes, com destaque para a Chicago Mercantile Exchange (Chicago, EUA), a Kansas City Board of Trade (Kansas, EUA) e o Mercado a Término de Buenos Aires (Buenos Aires, Argentina).

Este trabalho tem como objetivo estudar a viabilidade da implantação do contrato futuro de trigo na BMEFBOVESPA, o qual poderia se apresentar como alternativa de proteção às oscilações de preços para os agentes da cadeia produtiva do trigo no país e, consequentemente, como instrumento de planejamento da produção. Especificamente, pretende-se avaliar as condições necessárias para a implantação de um contrato futuro, traçando, em linhas gerais, características do setor tritícola no Brasil, bem como de potenciais participantes do mercado futuro de trigo.

No Brasil, estudos dessa natureza já foram realizados para outras commodities, como para suínos vivos, leite, carvão vegetal, madeira de reflorestamento, arroz e suco de laranja concentrado congelado por, respectivamente, Santos e Aguiar (2003), Siqueira (2003), Gomes (2006), Soares (2006), Costa (2008) e Clemente (2010).

Este estudo está organizado em outras três seções, além desta introdução: a seção 2 apresenta os desenvolvimentos da Teoria do Sucesso e Fracasso de Contratos Futuros, a qual dá suporte teórico a este estudo e aponta os procedimentos a serem adotados para a mensuração das variáveis relevantes à viabilidade de implantação de um novo contrato futuro; a seção 3 reúne os resultados da pesquisa; e, finalmente, a seção 4 apresenta as principais conclusões obtidas.

\section{Fundamentação Teórica e Procedimentos Metodológicos}

Este trabalho baseia-se na Teoria do Sucesso e Fracasso de Contratos Futuros, a qual surgiu da dificuldade que as bolsas encontram em prever se um contrato será bem sucedido ou falhará, e está amplamente difundida na literatura nacional. Segundo Pennings e Leuthold (1999), o conhecimento das características em níveis macro e micro permite responder duas questões complementares, que, em termos de viabilidade de lançamento do contrato futuro, são fundamentais:

a) a commodity é adequada para ser negociada em mercados futuros?

b) o tomador de decisão adotaria o contrato futuro?

Diante disso, apresentam-se, a seguir, os principais tópicos abordados pela Teoria do Sucesso e Fracasso de Contratos Futuros, nas perspectivas das aborda-

A relação completa das bolsas nas quais o contrato futuro de trigo é negociado encontra-se no site http://br.advfn.com. 
gens macro e micro. Concomitantemente, são explicados os procedimentos adotados e os métodos utilizados para a descrição e mensuração das variáveis em análise.

\subsection{Abordagem Macro}

\subsubsection{Tamanho do Mercado à Vista}

O mercado à vista deve ser suficientemente grande para atrair aos mercados futuros um número significativo de participantes potenciais, tanto hedgers quanto especuladores. Segundo Siqueira (2003), um amplo mercado físico consiste num grande volume de produção, demanda e estoques e, consequentemente, num grande número de firmas com atividade suficiente para atuar, em conjunto, no ambiente da bolsa de mercadorias, o que aumenta as chances das negociações desse contrato se desenvolver e ser bem sucedido.

Para dimensionar a participação do trigo em grão no agronegócio brasileiro, foi analisada a evolução de indicadores técnico-econômicos do setor tritícola, destacando-se produção anual, volume exportado e importado, consumo e produto gerado pelo setor.

\subsubsection{Grau de Atividade do Mercado à Vista}

Se um mercado é ativo, sendo que nele ocorre grande volume de transações da commodity em questão, o preço no mercado físico deve apresentar maior volatilidade, favorecendo a negociação em mercados futuros. Segundo Brorsen e Fofana (2001), há uma correlação positiva entre o grau de atividade do mercado à vista de uma commodity e seus volumes de comércio e posições abertas.

A avaliação do grau de atividade do mercado físico de trigo foi feita com base nas formas de comercialização do produto, na frequência das transações e no movimento de preços, como proposto por Siqueira (2003). Foram aplicados questionários junto aos elos da cadeia produtiva do trigo (produtores e indústria moageira), os quais abordavam aspectos mercadológicos e de funcionamento dos segmentos da cadeia, o que permitiu avaliar o grau de atividade do mercado. ${ }^{4}$

\subsubsection{Volatilidade de Preços do Ativo-Base}

Os preços no mercado físico devem estar sujeitos a oscilações de grande amplitude, o que altera a oferta e a demanda da commodity e aumenta o grau de incerteza dos preços num momento futuro. Isso representa um estímulo ao hedger, que almeja reduzir o risco de preço, e ao especulador, que deseja obter lucro com as variações de preços. Portanto, quanto maior for a volatilidade de preços, mais

Os questionários aplicados aos produtores e aos moinhos de trigo podem ser consultados em Schwantes (2010). 
atraente serão os contratos futuros para os hedgers e para os especuladores (COSTA, 2008).

O cálculo da volatilidade baseou-se na seguinte equação, disponível em Purcell e Koontz (1999):

$$
\sigma=\sqrt{\sum_{t=1}^{n-1} \frac{\left[\ln \left(\frac{P_{t}}{P_{t-1}}\right)-\mu\right]^{2}}{n-1} . m}
$$

em que $\sigma$ é o desvio padrão ou volatilidade; $P_{t}$ é o preço do ativo no período corrente; $P_{t-1}$ é o preço do ativo no período anterior; $t$ corresponde ao período; $\mu$ é a média das mudanças percentuais no preço do ativo; $n$ é o número de observações; $m=12$, o valor correspondente aos meses do ano.

\subsubsection{Perecibilidade e Possibilidade de Estocagem do Produto}

A possibilidade de estocagem de um produto é importante na medida em que permite o seu carregamento por períodos mais longos e reduz os riscos em relação à comercialização à vista. Segundo Capitani, Regazzini e Mattos (2010), os mercados futuros constituem-se em ferramenta de alocação temporal de estoques e, dessa forma, o hedge consiste em uma estratégia contra o risco de preço associado à manutenção de estoques. Nessa perspectiva, é desejável, portanto, que a commodity seja não perecível, podendo ser estocada por, pelo menos, alguns meses.

A descrição do trigo em grão comercializado no mercado nacional, mediante revisão bibliográfica e consulta a especialistas do setor, possibilitou a caracterização do produto quanto à sua durabilidade, aos sistemas de conservação do produto e à possibilidade de armazenamento da commodity.

\subsubsection{Grau de Homogeneidade e Mensurabilidade do Produto}

Se um produto não é homogêneo, torna-se difícil estabelecer um padrão de entrega. A dificuldade de padronização gera incerteza aos participantes do mercado, na medida em que estes não saberão qual produto está sendo, de fato, comercializado, e que tipo de produto será entregue. Quanto menos homogêneo for um ativo, maior será a dificuldade de comercializá-lo no futuro. Uma commodity de difícil mensuração cria margens para o aumento dos erros de avaliação do seu valor, exigindo que as bolsas estabeleçam medidas de controle a cada negócio e, portanto, aumentando os custos de transação (COSTA, 2008). 
Para verificar o grau de homogeneidade e a forma de mensuração do trigo em grão, foi feita uma pesquisa sobre as diferentes variedades de trigo produzidas no Brasil, bem como a forma como o produto é comercializado no mercado brasileiro, pois fornecem diretrizes importantes para a padronização e desenho do contrato futuro.

\subsubsection{Efetividade do Hedge com Contratos Futuros Alternativos para a Gestão de Risco ${ }^{5}$}

A preocupação do hedger consiste em minimizar o risco de preço. A existência de contratos futuros alternativos, em uma mesma bolsa ou em bolsas diferentes, pode levá-lo ao cross-hedge, ou seja, à utilização de um contrato futuro já existente, referenciado em outra commodity, cujos movimentos de preços estejam estritamente correlacionados com o instrumento à vista a ser hedgeado (BLACK, 1986).

Neste estudo, foram avaliadas operações de cross-hedge com o contrato futuro de trigo nas bolsas de Chicago e de Kansas City, nas quais se formam os preços internacionais da commodity, e na bolsa de Buenos Aires, pela proximidade com a principal região produtora de trigo no Brasil, a região Sul. Ainda, foram verificadas as possibilidades de se utilizar os contratos futuros de soja e milho negociados na BMËFBOVESPA como forma de proteção às oscilações de preços no mercado físico do trigo.

Utilizou-se para a análise da efetividade de hedge a estimação do modelo vetorial de correção de erro (VEC), que assumiu a forma: ${ }^{6}$

$$
\Delta P_{t}=\Gamma_{1} \Delta P_{t-1}+\Gamma_{2} \Delta P_{t-2}+\cdots+\Gamma_{n-1} \Delta P_{t-n+1}+\Pi P_{t-1}+\varepsilon_{t}
$$

em que $P_{t}$ é um vetor composto pelas variáveis de preços médios mensais do contrato futuro de trigo nas bolsas de Chicago, Kansas e Buenos Aires ou do contrato futuro de soja ou milho na BMEFBOVESPA e no mercado físico brasileiro de trigo; $\varepsilon_{\mathrm{t}}$ é um vetor de erros identicamente e independentemente distribuídos, $k \times 1$; e té o tempo, com frequência mensal.

A estimação da equação 2 não apresenta imediatamente a razão de hedge de mínima variância $\left(h^{*}\right)$ que deve ser aplicada pelos investidores. Para tanto, faz-se necessário o seu cálculo por meio da matriz de variâncias e covariâncias do modelo, definida como:

\footnotetext{
Aprofundamentos desta seção podem ser encontrados em Hull (2005) e Müller (2007).

Anteriormente à estimação do modelo vetorial de correção de erros, todas as séries de preços foram testadas quanto à estacionariedade. Também procurou-se identificar as relações de cointegração entre as séries temporais, que permitiram determinar as relações de longo prazo entre os preços no mercado físico e no mercado futuro. A descrição completa dos procedimentos adotados encontra-se em Schwantes (2010).
} 


$$
\sum=\left[\begin{array}{ll}
\sigma_{s}^{2} & \sigma_{s f} \\
\sigma_{f s} & \sigma_{f}^{2}
\end{array}\right]
$$

E, a partir da divisão entre covariância entre preços físicos e preços futuros e variância dos preços futuros, obteve-se a razão ótima de hedge. A efetividade do hedge, ${ }^{7}$ por sua vez, foi obtida por meio da equação 4:

$$
e=\frac{\operatorname{var}(p)-\operatorname{var}\left(h^{*}\right)}{\operatorname{var}(p)}
$$

em que e é a efetividade do hedge; var(p) é a variância da receita de um portfólio não protegido (sem hedge); e var( $h^{*}$ ) é a variância da receita de um portfólio protegido com a razão de hedge de mínima variância. A variância de um portfólio não protegido e de um portfólio protegido pode ser expressa, respectivamente, como:

$$
\begin{gathered}
\operatorname{var}(p)=\sigma_{s}^{2} \\
\operatorname{var}\left(h^{*}\right)=\sigma_{s}^{2}+\left(h^{*}\right)^{2} \sigma_{f}^{2}-2 h^{*} \sigma_{s f}
\end{gathered}
$$

em que var(p) é a variância da receita de um portfólio não protegido (sem hedge); $\operatorname{var}\left(h^{*}\right)$ é a variância da receita de um portfólio protegido com hedge; $\sigma_{s}^{2}$ é a variância dos preços à vista; $\sigma_{f}^{2}$ é a variância dos preços futuros; $\sigma_{s f}$ representa a covariância entre preços à vista e preços futuros; e $h^{*}$ é a razão ótima de hedge ou razão de hedge de mínima variância.

\subsubsection{Integração Vertical}

A existência de integração vertical (dois ou mais estágios sucessivos da cadeia produtiva controlados por uma mesma firma) relaciona-se negativamente ao sucesso de um contrato futuro, pois reduz o nível de concorrência no mercado à vista, tornando-o menos eficiente, e, também, elimina o risco de preços para os agentes integrados, o que reduz a demanda por instrumentos alternativos de gestão de risco de preços, como os contratos futuros (AGUIAR, 2003). A existência de integração vertical no setor tritícola brasileiro foi averiguada por meio de questionários aplicados aos triticultores e à indústria moageira.

A efetividade do hedge é a proporção de redução na variância da receita de um portfólio protegido em mercados futuros em relação à variância da receita de um portfólio não protegido. 


\subsubsection{Concentração de Mercado}

O mercado à vista deve aproximar-se ao máximo da competição perfeita para que não haja influência de forças externas na formação dos preços da commodity. Assim, se uma ou poucas firmas puderem controlar o mercado, os preços tenderão a refletir mais interesses individuais do que fundamentos do mercado, o que afasta os investidores desse mercado (COSTA, 2008).

A avaliação do grau de competição do mercado tritícola brasileiro nos segmentos de produção e moagem do cereal foi feita com base em pesquisa bibliográfica, buscando levantar informações sobre a estrutura de mercado em cada segmento e as imperfeições de mercado que podem existir, o que inviabilizaria o lançamento de um contrato futuro.

\subsubsection{Intervenção Governamental}

Os mecanismos de intervenção governamental, como a política de crédito rural, a política de seguro rural, os subsídios à produção, e, especialmente, a política de preços mínimos, podem apresentar-se como uma barreira ao desenvolvimento dos mercados futuros. Essas políticas oferecem algum tipo de proteção aos produtores, o que desestimula a procura por outras fontes de gerenciamento de risco de preço, como a utilização de contratos futuros.

Para a análise da intervenção do governo no mercado brasileiro de trigo, foram compilados os dados referentes à evolução dos mecanismos de política agrícola aplicados ao setor tritícola, à política de crédito rural e à política de garantia de preços mínimos (PGPM).

\subsection{Abordagem Micro}

A abordagem micro, ou de fatores subjetivos, relaciona-se às características dos agentes participantes do mercado que podem utilizar o contrato futuro do trigo como ferramenta de gerenciamento de risco de preços. Segundo Pennings e Leuthold (1999), tanto fatores financeiros quanto socioeconômicos apresentam impactos no processo de decisão dos potenciais participantes do mercado. Em termos financeiros, listam variáveis como exposição ou aversão ao risco do tomador de decisão, nível de riqueza da firma, oportunidades advindas da adoção do contrato, custos financeiros, financiamento da atividade e riscos inerentes à atividade. Em termos econômicos, apontam-se fatores ligados ao perfil do tomador de decisão quanto à utilização ou não do contrato, como escolaridade, experiência com o produto, tamanho da firma, ganho esperado com o hedge, idade, alavancagem e gerenciamento de risco.

Para retratar o perfil dos participantes do mercado físico do trigo no Brasil, foram aplicados questionários aos segmentos de produção e indústria de processamento do trigo no Brasil, abordando características de ordem socioeconômica 
e financeira, semelhantes aos utilizados nos trabalhos de Siqueira (2003), Costa (2008) e Clemente (2010).

Nos estados produtores de trigo no Brasil, procurou-se selecionar os municípios cuja produção de trigo, de acordo com o Censo Agropecuário 2006 (IBGE, 2010c), foi correspondente a mais de 1\% da produção total de cada estado. Os questionários impressos e digitais foram encaminhados a cooperativas agropecuárias e a empresas cerealistas de cada município, e, por meio destas, distribuídos a produtores de trigo. Em cinco municípios, se realizou pesquisa presencial. A amostra dos triticultores é probabilística estratificada, pois foi definida proporcionalmente ao tamanho de cada estrato da população (o estado) e, dentro de cada estrato (cada município), os produtores foram selecionados por amostragem aleatória simples. O tamanho da amostra foi definido conforme sugere Gil (1999) para amostras finitas, selecionando-se 145 unidades agropecuárias em um total de 29.561 estabelecimentos que produzem trigo em grão no Brasil, de acordo com o Censo Agropecuário 2006, realizado pelo IBGE (2010c) ${ }^{8}$.

Para as empresas da indústria moageira de trigo, não se determinou o tamanho da amostra, sendo que o questionário foi enviado por e-mail para todos os moinhos associados à Associação Brasileira da Indústria do Trigo (ABITRIGO, 2010), que totalizam 66 unidades.

A análise do perfil de produtores e da indústria moageira de trigo caracteriza o interesse dos hedgers em participar do mercado. Entende-se que, se houver interesse desta parcela de agentes em mercados futuros, possivelmente também haverá interesse dos demais participantes, como os especuladores.

\section{Resultados e Discussão}

\subsection{Abordagem Macro}

\subsubsection{Tamanho do Mercado à Vista}

Os indicadores relativos à oferta e à demanda interna do trigo em grão no Brasil são apresentados na Figura 1. Evidencia-se o déficit de produção em relação ao consumo da commodity no país, que, historicamente, tem sido observado em decorrência de diferentes fatores. ${ }^{9}$

\footnotetext{
$8 \quad$ O número de questionários distribuídos a cada estado produtor de trigo no país, bem como a participação dos municípios na produção nacional da commodity estão especificados em Schwantes (2010).

$9 \quad$ Ver Brum e Müller (2008).
} 
Figura 1 - Oferta e demanda de trigo no Brasil (1992/1993-2009/2010)

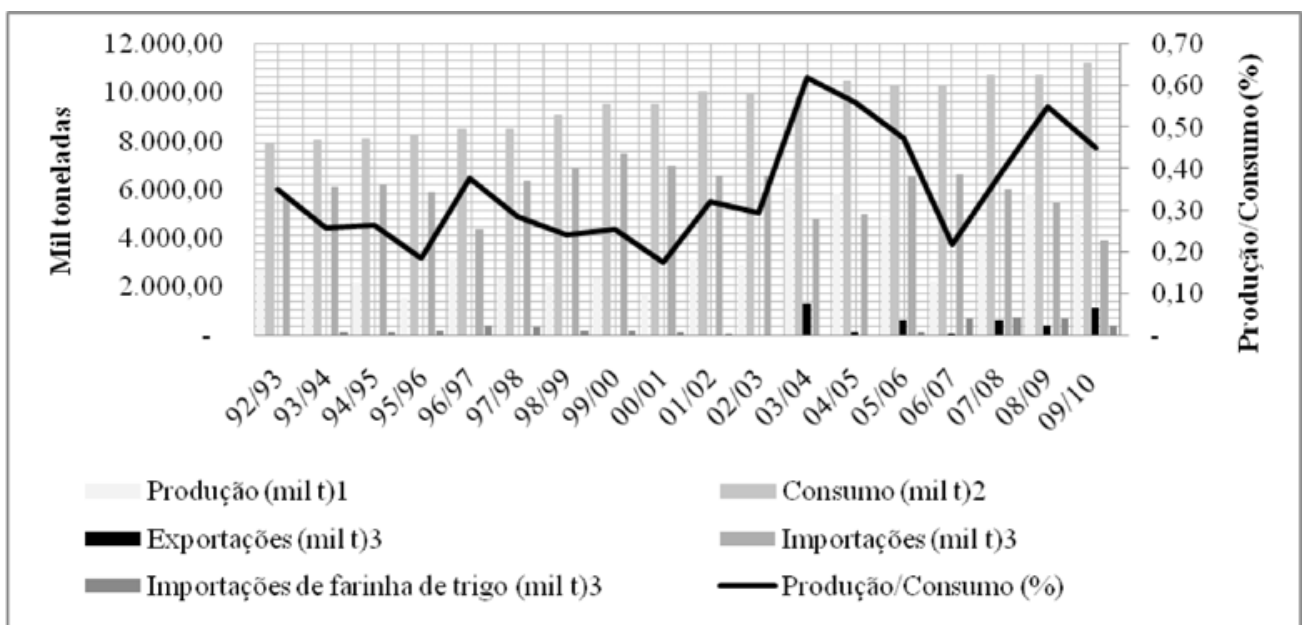

Fonte: Elaboração própria a partir de ${ }^{1}$ Conab (2010); ${ }^{2}$ USDA (2012); ${ }^{3}$ Brasil (2010).

Brum e Müller (2008) destacam que, de uma situação de quase autossuficiência em 1986/1987 (6,5 milhões de toneladas), após a desregulamentação do setor, o país retrocedeu para uma produção média anual que varia entre 4 e 6 milhões de toneladas, abastecendo, poucas vezes, pelo menos metade da demanda interna. A produção do cereal só voltou a ser estimulada recentemente, por elevações de preços conjunturais, como na safra 2003/2004.

Não existem perspectivas de aumentos expressivos da oferta nacional do produto, a qual tem abastecido, em média, 40,4\% do consumo interno do cereal, na década de 2000. Desse modo, se por um lado o mercado consumidor apresenta-se relativamente grande em relação à capacidade de abastecimento do setor, por outro o mercado nacional fornecedor da commodity parece pouco expressivo para viabilizar o lançamento de um contrato futuro. Para efeitos de comparação, a Figura 2 apresenta o valor total da produção de trigo em grão, assim como de commodities cujo contrato tem sido negociado com sucesso na BMEFBOVESPA e, ainda, o valor da produção do algodão, cujas negociações do contrato foram encerradas em 2008, para o período de 2000 a 2008. 
Figura 2 - Valor total da produção (VTP) brasileira de produtos agrícolas selecionados, de 2000 a 2008 (em milhões de reais)

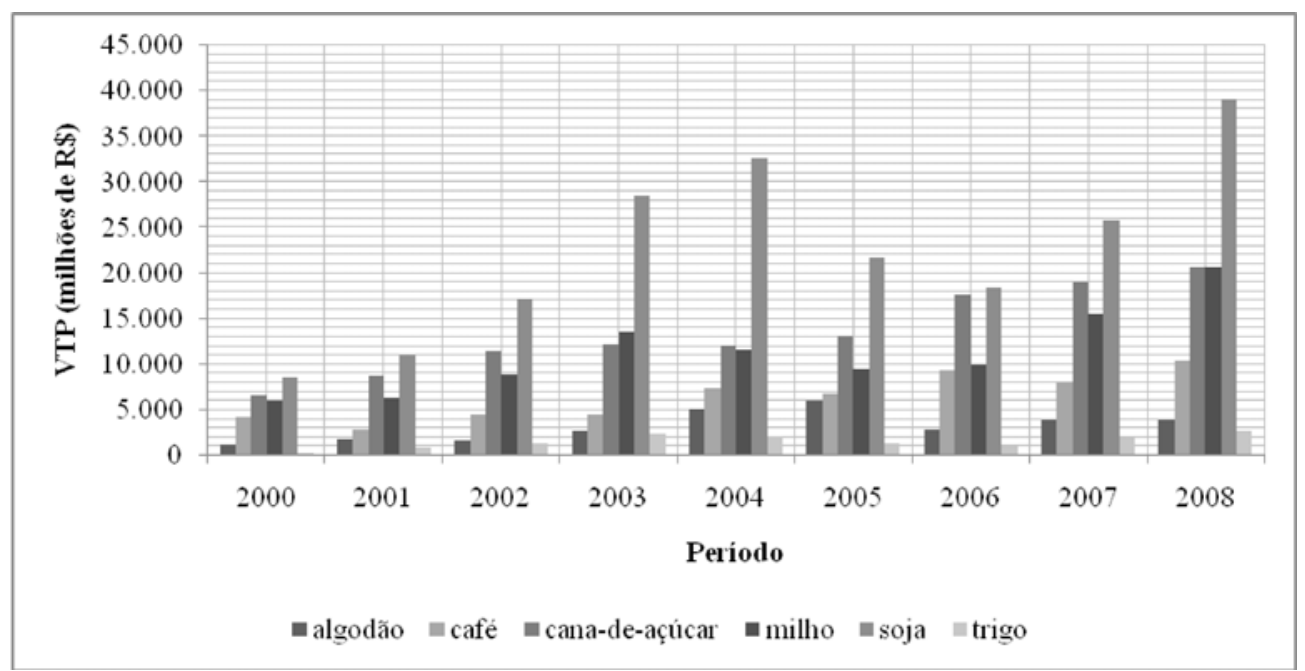

Fonte: Elaboração própria a partir de dados do IBGE (2010a).

A literatura não tem definido um volume mínimo de comércio no mercado físico que viabilize a implantação e garanta o sucesso de um derivativo agropecuário. No entanto, Colling (1996 ${ }^{10}$ apud SOUZA, 1998) ressalta que mercados físicos inferiores à US $\$ 2$ bilhões raramente resultam em contratos futuros bem sucedidos na Chicago Board of Trade (CBOT). Na Figura 2, observa-se que o mercado físico do trigo em grão eventualmente alcança o volume de 2 bilhões de reais em valor total da produção.

Em comparação com os mercados de soja, milho, café e cana-de-açúcar que tem contratos já consolidados na BMEJFBOVESPA, tanto o mercado físico do trigo, quanto o mercado disponível do algodão, cujo contrato não se firmou em mercados futuros no Brasil, são relativamente pequenos, o que dificultaria o sucesso desse contrato. Conclui-se, portanto, que o tamanho do mercado disponível de trigo não é grande o suficiente para comportar um contrato futuro.

\subsubsection{Grau de Atividade do Mercado à Vista e Formas de Comercialização}

No Brasil, a comercialização das safras do trigo em grão tem ocorrido, basicamente, por meio dos agentes de comercialização, o que inclui cooperativas e empresas cerealistas, que compram a produção dos produtores e vendem diretamente aos segmentos mais a jusante da cadeia tritícola. Segundo Brum e Müller (2008), as cooperativas compram o cereal dos produtores no sistema de balcão, que consiste na compra direta de qualquer volume do produto, com o preço es-

10 COLLING, P. Factors impacting the potential success of futures markets. In: ENCONTRO PAN-AMERICANO DE BOLSAS DE MERCADORIAS, 4., Rio de Janeiro, 1996. Anais... Rio de Janeiro: 1996. 
tabelecido em função da qualidade e no sistema de lotes, não existindo, portanto, nenhum tipo de contratação na comercialização nesse mercado.

Ainda, a pesquisa de campo realizada junto aos elos da cadeia produtiva do trigo no Brasil permite verificar a frequência das transações de compra e venda de trigo em grão no mercado. Dos 119 produtores de trigo entrevistados, 47,06\% declararam armazenar trigo na safra para vendê-lo posteriormente, aguardando a melhoria dos preços, enquanto 52,94\% dos entrevistados afirmaram não armazenar o trigo para vendê-lo na entressafra, mas vendê-lo assim que colhido.

No que se refere à frequência das transações com moinhos, os maiores percentuais relacionam-se, respectivamente, aos produtores que não responderam a essa pergunta (31,09\% dos entrevistados) e aos produtores que vendem o produto assim que colhido (29,41\% dos respondentes). Entende-se, com base no percentual dos produtores que afirmaram não armazenar trigo $(52,94 \%)$, que os produtores que não responderam ao questionamento também realizam a venda de suas safras de trigo assim que o cereal é colhido. Assim, cerca de $50 \%$ a $60 \%$ dos produtores não armazenam o cereal para venda em época de entressafra. Esse resultado está diretamente ligado ao fato dos triticultores fazerem uso, em geral, de financiamento bancário para o plantio do trigo e, dessa forma, os produtores menos capitalizados comercializam a sua produção na safra, pois a maior parcela desses empréstimos vence nesse período. Já os produtores mais capitalizados optam por vender em períodos de entressafra, quando esperam obter preços mais compensadores (LEISMANN, 2002).

Segundo Brum e Müller (2008), a comercialização da farinha de trigo na indústria de segundo processamento (indústria de massas e biscoitos) também passou a ser feita no mercado livre, após a desregulamentação, sobretudo no sistema de lotes. A pesquisa de campo realizada junto às indústrias de processamento de trigo confirma esse fato. Entre os dez moinhos que responderam ao questionário, apenas um declarou comercializar a farinha de trigo com utilização de contrato.

Como as transações no mercado tritícola ocorrem, em geral, no mercado à vista, com pouca utilização de contratos e sem frequência definida das vendas de trigo aos moinhos, a forma como os negócios ocorrem no mercado à vista é um fator favorável à implantação de um contrato futuro do cereal no país.

\subsubsection{Volatilidade de Preços do Ativo-Base}

O cálculo da volatilidade do preço do trigo em grão foi realizado para os estados do Paraná e do Rio Grande do Sul, que são os maiores produtores da commodity no Brasil e para o estado de São Paulo, o qual concentra parcela significativa das indústrias moageiras de trigo cadastradas junto à Abitrigo (2010) e, em consequência, absorve a maior parte do trigo produzido no Brasil. 
Na Tabela 1, apresentam-se os resultados dos cálculos de volatilidade dos preços mensais do quilograma de trigo em grão para os três estados mencionados, bem como os resultados encontrados para o cálculo da volatilidade dos preços mensais das commodities negociadas junto a BMEFBOVESPA, conforme a equação 1 .

Tabela 1 - Volatilidade de preços físicos do trigo e das principais commodities agrícolas negociadas na BMEFBOVESPA, no período de janeiro de 1997

a maio de 2010

\begin{tabular}{l|c}
\hline \multicolumn{1}{c|}{ Commodity } & Volatilidade (\%) \\
\hline Algodão $(\mathrm{R} \$ / \mathrm{kg})$ & 10,33 \\
Boi gordo $(\mathrm{R} \$ / 15 \mathrm{~kg})$ & 11,10 \\
Café em coco $(\mathrm{R} \$ / \mathrm{kg})^{1}$ & 22,10 \\
Cana-de-açúcar $(\mathrm{R} \$ / \mathrm{t})$ & 12,96 \\
Milho $(\mathrm{R} \$ / \mathrm{kg})$ & 24,89 \\
Soja $(\mathrm{R} \$ / \mathrm{kg})$ & 17,33 \\
Trigo - São Paulo $(\mathrm{R} \$ / \mathrm{kg})$ & 23,80 \\
Trigo - Paraná $(\mathrm{R} \$ / \mathrm{kg})$ & 24,69 \\
Trigo - Rio Grande do Sul $(\mathrm{R} \$ / \mathrm{kg})$ & 19,00 \\
\hline
\end{tabular}

Fonte: Elaboração própria a partir de resultados da pesquisa.

Notas: 1) exclusivamente para o café, o período considerado refere-se à janeiro de 1997 a novembro de $2006 ; 2$ ) as séries mensais dos preços recebidos pelos produtores pelo quilograma de trigo em grão nos estados considerados foram coletadas no banco de dados da Fundação Getúlio Vargas, à exceção da série para o estado de São Paulo, que foi adquirida junto à Editora Agronômica Safras e Mercado Ltda. Esses dados foram deflacionados pelo índice geral de preços do mercado (IGP-M), tendo como período base maio de 2010.

A variação nos preços do trigo, nos três estados considerados, é semelhante à volatilidade de preços dos cereais que possuem contratos futuros bem sucedidos comercializados na BMEFBBOVESPA, soja e milho, cujos preços apresentaram variações médias no período de janeiro de 1997 a maio de 2010 de $17,33 \%$ e 24,9\%, respectivamente.

A grande variação de preços no mercado físico de trigo constitui-se em fator importante para o lançamento de um contrato futuro do cereal, pois sinaliza para a necessidade dos produtores e da indústria moageira e de segundo processamento buscarem mecanismos de gerenciamento de risco de preços. Esse resultado apresenta-se como um ponto favorável à implantação do contrato futuro de trigo no Brasil.

\subsubsection{Perecibilidade e Possibilidade de Estocagem do Produto}

No Brasil, o trigo é, em sua maioria, de inverno, cultivado em sistema de sequeiro, sendo plantado no inverno e se desenvolvendo na primavera. Assim, como o ciclo anual de maturação do grão oscila em torno de 90 a 180 dias, a cultura está 
exposta à possibilidade de geadas fortes no início do ciclo. Já a colheita ocorre em período chuvoso (de julho a novembro). No entanto, a possibilidade de secagem propicia um melhor planejamento da colheita e o emprego mais eficiente de equipamentos e de mão de obra, mantendo a qualidade do trigo colhido (EMBRAPA, 2010). Portanto, há a possibilidade de estocagem do cereal. Cabe ressaltar que a possibilidade de armazenamento do produto e a sua perecibilidade, entretanto, estão relacionadas mais à questão de estratégia econômica do que à viabilidade de implantação de um contrato futuro, pois tanto hedgers quanto especuladores podem encerrar suas posições por reversão ou por liquidação financeira.

\subsubsection{Grau de Homogeneidade e Mensurabilidade do Produto}

No caso do trigo em grão, a Instrução Normativa $n^{\circ} 7$, da Secretaria de Apoio Rural e Cooperativismo (Sarc) do Ministério da Agricultura, Pecuária e Abastecimento (BRASIL, 2001), de 15 de agosto de 2001, ${ }^{11}$ aprovou o Regulamento Técnico de Identidade e de Qualidade do Trigo, vigente até a presente data, para fins de classificação do produto e uniformização de critérios e procedimentos e o uso de terminologia técnica única em caso de comercialização de trigo nacional ou importado.

Segundo a instrução normativa n. 7, o trigo está classificado em cinco classes comerciais (brando, pão, melhorador, outros usos e durum), definidas em função das determinações analíticas de alveografia (força do glúten) e número de queda. Essa classificação comercial do cereal estima a sua aptidão tecnológica, ou seja, com base nos valores de força geral de glúten (W), da relação tenacidade/extensibilidade $(\mathrm{P} / \mathrm{L})$ e do número de queda $(\mathrm{NQ})$, indica-se o uso do trigo por produto. Ainda, classifica-se o trigo em três tipos (tipo 1, 2 ou 3), determinados em função do limite mínimo do peso do hectolitro $(\mathrm{PH})$ e dos limites máximos dos percentuais de umidade, de matérias estranhas e impurezas e de grãos avariados.

Segundo Café et al. (2003), no Brasil, as características e variedades de trigo são diferentes em cada região produtora. A Figura 3 apresenta a distribuição da produção de trigo por região no Brasil, de acordo com as melhores condições edafoclimáticas para as diferentes variedades, segundo a aptidão tecnológica de cada variedade.

Esta instrução normativa foi publicada no Diário Oficial da União, em 21 de agosto de 2001, Seção I, páginas 33 a 35. 


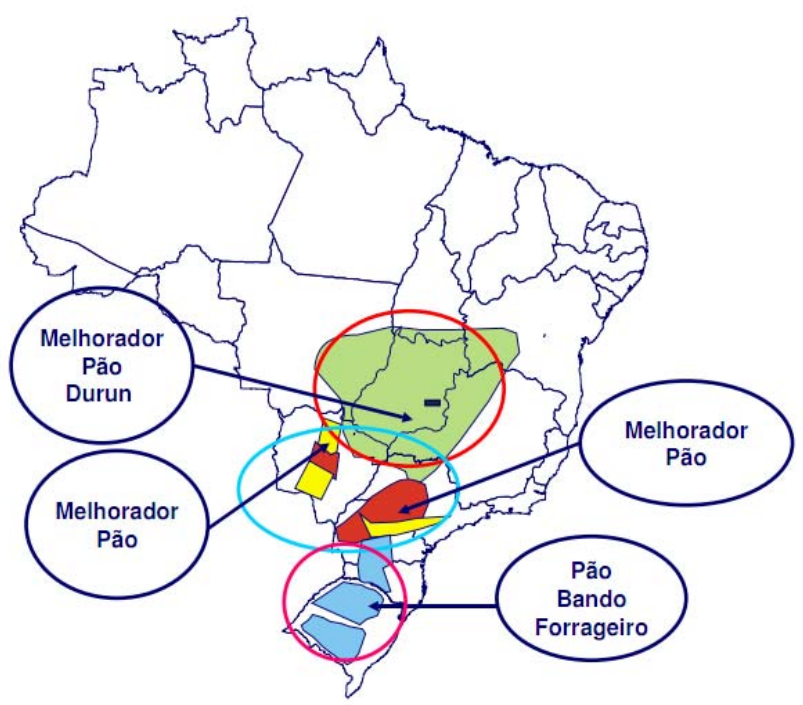

Fonte: Bacaltchuk e Ignaczak (2002 ${ }^{12}$ apud ROSSI; NEVES, 2004).

A produção dos tipos pão e melhorador, destinados à fabricação de pão francês, outros pães e de massas alimentícias, localiza-se no norte do Paraná, no sul de São Paulo, em Mato Grosso do Sul e no cerrado, enquanto na parte sul do Paraná e em todo o Rio Grande do Sul as condições são propícias para a produção do trigo classificado como brando, que é utilizado na fabricação de biscoitos, pizzas e bolos. O trigo classificado como outros usos é resultante da mistura de vários tipos de trigo e seu melhor rendimento ocorre na fabricação de massas que utilizam ovos ou outras substâncias para a formação de liga. ${ }^{13}$

$\mathrm{Na}$ safra de 2009, a produção de trigo pão/melhorador foi predominante sobre a produção do trigo brando, alcançando $71,5 \%$ do total colhido no ano (EMBRAPA, 2010). No entanto, a qualidade do grão produzido no Brasil varia bastante de uma safra a outra, por conta de adversidades climáticas, como secas, geadas e chuvas na colheita, que prejudicam as condições físicas do produto entregue pelo produtor e a qualidade para a industrialização (CAFÉ et al., 2003; ROSSI; NEVES, 2004). Assim, a padronização do produto pode ser um fator de dificuldade para o lançamento de um contrato futuro, nos casos em que ocorre a entrega física da mercadoria.

$12 \quad$ BACALTCHUK, B.; IGNACZAK, J. C. Aspectos relevantes da cadeia do trigo. In: ENCONTRO DE PLANEJAMENTO DAS LAVOURAS DE INVERNO, 2002, Erechim. Anais... Erechim, 2002.

13 O trigo classificado como durum, utilizado no preparo de massas especiais, não é produzido no Brasil. No cerrado, em regime de irrigação e em ambientes bem definidos, seria possível produzi-lo. 


\subsubsection{Efetividade do Hedge com Contratos Futuros Alternativos para a Gestão de Risco}

Inicialmente, determinou-se a ordem de defasagens do modelo VAR com base nos critérios de informação de Akaike, Schwarz e Hannan-Quinn. Aplicou-se o teste de cointegração de Johansen para investigação de existência de relação de equilíbrio de longo prazo entre cada par de séries analisadas e estimou-se o vetor de cointegração. Em seguida, obteve-se a matriz de variâncias e covariância entre os preços nos mercados físico e futuro e, por meio desta, obteve-se a razão ótima de hedge para cada contrato em análise e a efetividade de se utilizar cada contrato em estudo como instrumento de proteção. Os resultados estão apresentados na Tabela 2.

Tabela 2 - Resultados da razão ótima de hedge e da efetividade do hedge com contratos futuros alternativos

\begin{tabular}{l|c|c}
\hline \multicolumn{1}{c|}{ Contrato futuro } & $\begin{array}{c}\text { Razão de hedge } \\
\text { otima }\left(\boldsymbol{h}^{*}\right)\end{array}$ & $\begin{array}{c}\text { Efetividade do } \\
\text { hedge }(\boldsymbol{e})\end{array}$ \\
\hline Soja (SOJ-BMEF) & 0,2415 & 0,4235 \\
Milho (CNI-BMEF) & 0,3614 & 0,0879 \\
Trigo (Kansas City Board of Trade) & 0,2004 & 0,1097 \\
Trigo (Chicago Mercantile Exchange) & 0,1384 & 0,1822 \\
Trigo (Mercado a Término de Buenos Aires) & 1,01 & 0,2513 \\
\hline
\end{tabular}

Fonte: Elaboração própria a partir de resultados da pesquisa.

Notas: 1) as cotações mensais da saca de $60 \mathrm{Kg}$ dos contratos de soja (SOJ) e milho (CNI) são médias aritméticas da cotação média diária divulgada pela BMËFBOVESPA. Os preços à vista para a saca de $60 \mathrm{Kg}$ de trigo correspondem ao preço médio mensal no estado do Paraná, disponibilizados pelo site Agrolink; 2) as séries diárias da cotação média do contrato futuro de trigo (KW) negociado na Kansas City Board of Trade foram obtidas no próprio site da bolsa KCBT e transformados em US $\$ /$ t. Foi construída a média aritmética das cotações diárias praticadas em cada mês de vencimento. Para o mercado físico, utilizou-se o preço médio mensal (em US\$/t) na praça de Maringá (PR), cujos dados foram adquiridos da Editora Agroeconômica Safras e Mercado Ltda; 3) os dados da cotação média mensal do contrato futuro de trigo negociado na Chicago Mercantile Exchange têm como fonte o site Barchart. Esses dados receberam o mesmo tratamento dos obtidos na Kansas City Board of Trade; 4) os dados do contrato negociado no Mercado a Término de Buenos Aires (em US $\$$ t t) foram obtidos no site da própria bolsa. Para todos os contratos, utilizou-se o primeiro vencimento em aberto.

Pode-se inferir que os preços médios mensais de trigo praticados no estado do Paraná apresentam fraca relação com os preços do cereal praticados em mercados futuros nas bolsas de Kansas, Chicago e Buenos Aires e, também, com os preços futuros da soja e do milho na BMËFBOVESPA. Dessa forma, esses contratos não seriam concorrentes do contrato futuro de trigo lançado no Brasil, e, assim, pode-se considerar esse fator como um aspecto positivo à implementação do contrato futuro de trigo pela BMEFBOVESPA. 


\subsubsection{Integração Vertical}

Brum e Müller (2008) destacam que a cadeia nacional do trigo desorganizou-se após a desregulamentação da comercialização e da industrialização do cereal. Nesse sentido, os autores ressaltam que, a montante, as unidades produtivas, em geral, não se relacionam diretamente com os fabricantes de insumos, salvo no caso dos grandes produtores, que realizam suas compras diretamente na indústria. Entretanto, grande parte dos produtores se relaciona com cooperativas para desfrutar vantagens nas compras em comum, beneficiando-se de preços melhores, já que elas operam em grandes escalas e com margens reduzidas.

Da mesma forma, os segmentos a jusante apresentam relações insípidas com os demais elos da cadeia produtiva e, segundo os autores, um dos motivos refere-se ao tipo de matéria-prima produzida. Embora o trigo nacional seja semelhante ao produto importado, nem sempre oferece melhores preços e, raramente, melhor qualidade e condições de pagamento. Dessa maneira, a indústria moageira prefere adquirir sua matéria-prima no mercado internacional, privilegiando-se das condições oferecidas.

Brum e Müller (2008) observam que, embora incipiente e de forma isolada, existem alguns contratos entre a atividade agrícola e a indústria moageira, principalmente entre pequenos e médios moinhos. Esse acordo é realizado mediante o adiantamento pelos moinhos de parte dos recursos que seriam pagos na comercialização do trigo. Através desse mecanismo, uma parte dos produtores pode realizar o plantio da safra futura sem as opções dos mecanismos financeiros tradicionais, a exemplo do crédito rural.

A pesquisa realizada junto a alguns triticultores reflete essa realidade. Dos 119 produtores que responderam ao questionário, 56 declararam utilizar algum contrato na comercialização com cooperativas ou moinhos. Desses 119 produtores, 115 declararam comercializar a maior parte de sua produção com as cooperativas agropecuárias e apenas 3 comercializam diretamente com moinhos, o que aponta para a pouca expressividade de qualquer tipo de compromisso firmado entre produtores rurais e moinhos, e, portanto, para a não existência de integração vertical no setor. Por outro lado, o número elevado de produtores que vendem a sua produção às cooperativas refere-se ao compromisso que os associados têm em entregar as suas safras para serem comercializadas via cooperativa, já que desfrutam das compras de insumos de produção em conjunto. Dessa forma, a integração vertical não representa um entrave ao sucesso do contrato futuro de trigo no Brasil.

\subsubsection{Concentração de Mercado}

Neste estudo, faz-se a caracterização dos produtores rurais e da indústria moageira, pois esses agentes são os potenciais usuários de contratos futuros de 
trigo no Brasil, atuando como hedgers. Entende-se que, se a estrutura do mercado à vista do produto é propícia para o lançamento de um contrato futuro, os especuladores, por sua vez, também participarão desse mercado, pois objetivam obter lucro, independentemente do ativo negociado em contrato futuro.

Os produtores do cereal no mercado interno, por serem pequenos em relação ao mercado, operam numa estrutura concorrencial, na qual tomam o preço como dado. Da mesma forma, as cooperativas de trigo e empresas cerealistas não têm o poder de determinar o nível de preços do grão, tomando-o no mercado e apenas repassando aos produtores. A análise da evolução da triticultura no Brasil mostra a concentração das propriedades rurais, conforme dados dos censos agropecuários de 1995-1996 e 2006. Em 1995-1996, existiam cerca de 64 mil estabelecimentos agrícolas nos quais havia produção de trigo, sendo que 18.814 situavam-se no estado do Paraná e 33.677 no Rio Grande do Sul. Esses dois estados reuniam $82,12 \%$ dos estabelecimentos com exploração tritícola, bem como 91\% da área colhida e $91,24 \%$ da produção de trigo no país. A produção no Brasil concentrava-se nos estabelecimentos de 20 a menos de 50 hectares $(22,75 \%)$ e nas propriedades de 50 a menos de 100 hectares (17,8\%). Contudo, o estrato de área colhida com maior número de estabelecimentos correspondia às propriedades com menos de 5 hectares, que representavam $55 \%$ do total de estabelecimentos com produção de trigo.

Em 2006, observou-se a concentração da produção em propriedades de 200 a menos de 500 hectares, que representaram $25,11 \%$ do total de trigo produzido no país, sendo que o tamanho médio dos estabelecimentos foi de 279,51 hectares. Em seguida, o estrato de área colhida de 100 a menos de 200 hectares produziu o equivalente a 18,5\% da produção total do país. Enquanto 30.515 estabelecimentos agropecuários produtores de trigo no estrato de menos de 5 hectares deixaram de produzir, nos estratos de área acima de 50 hectares ocorreu expressiva elevação do número de estabelecimentos, com destaque para os estratos de área acima de 200 hectares, nos quais surgiram 761 novos estabelecimentos entre 1995 e 2006.

Embora os dados dos censos agropecuários de 1995-1996 e de 2006 apontem para a concentração das propriedades rurais, os produtores de trigo ainda são os agentes da cadeia que se apresentam em maior número. No segmento de moagem de trigo, por outro lado, o que se observa é a concentração das firmas. Segundo Colle (1998), de modo geral, a indústria moageira apresenta características de um oligopólio concentrado, no qual as firmas operam sob diferentes condições de custos, decorrente de diferentes combinações no uso de fatores e das diferenças qualitativas e quantitativas nos equipamentos utilizados, sendo as grandes empresas do setor que ditam as condições de comercialização do trigo em grão a cada safra. 
A indústria moageira tem o maior número de unidades industriais localizadas no sul do Brasil, onde se situam cerca de $60 \%$ de todos os moinhos do Brasil. Colle (1998) ressalta que nessa região o setor é desconcentrado e caracterizado pela presença de pequenas unidades fabris, o que se comprova pelo volume de moagem efetiva em 2008 (3,34 milhões de toneladas), volume aproximado da região sudeste, que sitia 62 unidades de moagem de trigo para um volume de moagem de, aproximadamente, 3 milhões de toneladas.

A região nordeste processou, em 2008, 2,33 milhões de toneladas, contando com apenas 46 unidades industriais. $\mathrm{O}$ volume de trigo em grão processado pela região correspondeu a $25,8 \%$ do total no país. Observa-se, assim, que, nas regiões sudeste e nordeste, a indústria moageira é mais concentrada. Ressalva-se, ainda, que a indústria moageira de trigo no Brasil possuía, em 2007, capacidade ociosa de cerca de $43,3 \%$.

Embora o setor se apresente bastante concentrado, Rossi e Neves (2004) explicam que as margens de lucro são reduzidas nessa atividade. Assim, a indústria moageira poderia aumentar suas margens de lucro operando em mercados futuros, pois dessa maneira é possível conhecer o custo e a qualidade da matéria-prima anteriormente à aquisição.

Por isso, infere-se que, em geral, a concentração das unidades produtoras de trigo e das indústrias de primeiro processamento de trigo no Brasil não traz, em princípio, entraves ao lançamento do contrato futuro de trigo no país. Embora tenha se observado aumento da concentração de mercado nos segmentos acima mencionados, há a possibilidade do contrato futuro de trigo obter sucesso, dadas as perspectivas de expansão do segmento de moagem.

\subsubsection{Intervenção Governamental}

No Brasil, a triticultura é um setor historicamente caracterizado pela intervenção governamental. Mesmo após o processo de liberalização da economia, o setor público, por meio do financiamento agrícola e dos instrumentos da PGPM, atua na regulação desse mercado.

No período de 1999 a 2010, o total de financiamento de custeio da lavoura de trigo concedido pelo governo federal cresceu a uma taxa geométrica de $19,69 \%$, alcançando R $\$ 1,08$ bilhão em 2010. Em 2009, o trigo foi a sexta cultura que mais recebeu recursos, o equivalente a $4,77 \%$ dos empréstimos do governo federal para a agricultura. As culturas que mais receberam recursos para financiamento da produção no mesmo ano (soja: $32,2 \%$ do total; milho: $17,4 \%$; café: 11,02\%; cana-de-açúcar: 9,2\%) têm negociações em mercados futuros na bolsa do Brasil. O volume de crédito emprestado pelo governo federal, em 2009, financiou o equivalente a $65 \%$ da área cultivada com trigo naquele ano. 
Já o apoio do governo federal à comercialização do trigo ${ }^{14}$ em grão tem ocorrido por meio das aquisições do governo federal (AGF), das aquisições por meio dos Contratos de Opção de Venda (COV), do Prêmio de Risco de Opção Privada (PROP) e do Prêmio para Escoamento do Produto (PEP), como mostra a Tabela 3, além das Compras da Agricultura Familiar (CAF).

Tabela 3 - Apoio do governo federal à comercialização do trigo em grão (em mil toneladas)

\begin{tabular}{|c|c|c|c|c|c|c|c|c|c|c|}
\hline Item & $2000 / 01$ & $2001 / 02$ & $2002 / 03$ & $2003 / 04^{*}$ & $2004 / 05^{* *}$ & $2005 / 06$ & $2006 / 07$ & $2007 / 08$ & $2008 / 09$ & $2009 / 10$ \\
\hline AGF direta & & & & & 269,7 & 31,9 & & 237,1 & 21,3 & 378,8 \\
\hline Vendas PEP & & & & & & & & & & \\
\hline Ofertado & & & & & 1790 & 1950 & & 1490 & 2530 & 4661 \\
\hline Vendido & & & & & 433,8 & 1184,2 & & 425,5 & 1113,2 & 3261,3 \\
\hline PROP & & & & & & & & & & \\
\hline Ofertado & & & & & & 300,2 & & & & \\
\hline Vendido & & & & & & 153,4 & & & & \\
\hline $\mathrm{COV}$ & & & & & & & & & & \\
\hline Ofertado & 1000,1 & & & 801,4 & 657 & & & & 1573,1 & \\
\hline Vendido & 281,9 & & & 517,7 & 650 & & & & 1103,2 & \\
\hline Exercício & 21,5 & & & 151,7 & 576.9 & & & & 460,8 & \\
\hline Apoio total & 281,9 & & & 517,7 & 1353.5 & 1369,4 & & 662,6 & 2237,7 & 3635,1 \\
\hline Produção & 1658,4 & & & 6073,5 & 5845.9 & 4873,1 & 2233.7 & 4097,1 & 5884,7 & 5026,3 \\
\hline Participação & $17 \%$ & & & $8,5 \%$ & $23,2 \%$ & $28,1 \%$ & & $16,2 \%$ & $38 \%$ & $72,3 \%$ \\
\hline
\end{tabular}

Fonte: Conab (2010).

Notas: *As opções vendidas em 2003 tiveram o seu exercício em 2004.

**As opções vendidas em 2004 tiveram o seu exercício em 2005.

A Tabela 3 mostra que o COVPA e o PEP têm sido mais utilizados na comercialização de trigo em detrimento do PROP, que foi utilizado apenas na safra 2005/2006, quando da sua criação. O COVPA e o PEP foram criados em 1997 e são instrumentos públicos de intervenção direcionada no mercado, com características seletivas (BACHA, 2012).

A comercialização de trigo via PEP teve seus volumes mais elevados nas safras de 2005/2006, 2008/2009 e 2009/2010, nas quais o volume vendido por esse mecanismo equivaleu a, aproximadamente, $25 \%, 19 \%$ e $65 \%$, respectivamente, da produção nacional da commodity. Entre os moinhos visitados na pesquisa de campo realizada, houve a constatação de que o governo demorou para fazer o pagamento do prêmio na safra 2009/2010, e esse fato constitui-se em um fator de desestímulo à aquisição do trigo nacional pelos moinhos.

O governo federal disponibiliza, ainda, auxílio à agricultura familiar para a cultura do trigo, tanto por meio de financiamento de custeio ao cultivo de trigo

$14 \quad$ Maior detalhamento acerca dos instrumentos de apoio à comercialização utilizados pela PGPM podem ser encontrados no Plano Agrícola e Pecuário 2011/2012, disponível em: <www.agricultura.gov.br $>$. 
com taxas de juros diferenciadas, alcançando o máximo de 4,5\%, dependendo do valor financiado, como por meio de compras diretas da agricultura familiar dos agricultores enquadrados no Programa Nacional de Fortalecimento da Agricultura Familiar (Pronaf), quando o preço de mercado estiver abaixo do preço de referência. O número de contratos de financiamento concedido à agricultura familiar, em 1999, perfazia 4.460, enquanto, em 2010, havia o registro de 16.666 contratos nessa modalidade. O montante total de crédito rural destinado à produção de trigo para a agricultura familiar cresceu à taxa de $29,88 \%$ ao ano, no período de 1999 a 2010, alcançando $R \$ 190.379 .810,59$ no ano de 2010.

O que se evidencia é a intervenção estatal ainda em grande proporção, ressaltando-se as duas últimas safras, apresentadas na Tabela 3, nas quais o governo interveio por meio dos mecanismos de garantia de preços aos produtores em montantes equivalentes a $38 \%$ e $72 \%$ da produção do setor, respectivamente. As políticas de garantia de renda ao setor tritícola são descontínuas e, a cada safra, o governo utiliza instrumentos diferentes de apoio ao setor. Dessa forma, os mecanismos tradicionais de gerenciamento de risco de preços, sustentados pelo governo federal, constituem-se em um desestímulo à procura de novos instrumentos pelos agentes desse mercado, de modo que o volume de transações em bolsa de mercadorias poderia ser prejudicado por esse fator e deixar o contrato com baixa liquidez.

\subsection{Abordagem Micro}

Para verificar o interesse dos participantes do mercado à vista do trigo no Brasil em adotar o contrato futuro de trigo, foram aplicados questionários com 32 questões de múltipla escolha a produtores de trigo e à indústria moageira. Esses questionários diferenciaram-se de acordo com o segmento da cadeia tritícola em estudo, mas, em geral, abordaram aspectos relacionados à caracterização do entrevistado, informações sobre a propriedade rural ou sobre a estrutura administrativa da empresa, aspectos concernentes à comercialização agrícola do trigo ou de aquisição da matéria-prima pelas indústrias de processamento e, finalmente, conhecimento e utilização de mercados futuros.

Foram entrevistados 119 produtores de trigo, por meio de cooperativas e empresas cerealistas, dos estados do Rio Grande do Sul (77 entrevistados), Paraná (31), Minas Gerais (2), Goiás (4) e Distrito Federal (5). Essa amostra corresponde a $0,4 \%$ do total de estabelecimentos agropecuários no Brasil em que ocorre a produção de trigo. Na indústria moageira, foram contatadas as 66 empresas associadas à Associação Brasileira da Indústria do Trigo (ABITRIGO, 2010). Porém obteve-se o retorno de apenas dez questionários respondidos.

O bloco de questões concernentes às informações sobre a propriedade dos entrevistados permite destacar que: 
a) $21,85 \%$ das propriedades possuem área de 200 a menos de 500 hectares, seguidas pelas propriedades de 100 a menos de 200 hectares (19,33\%) e de propriedades de 50 a menos de 100 hectares (17,65\%);

b) 50,42\% dos entrevistados declararam que a propriedade é própria e 44,53\% informaram que uma parte da propriedade é arrendada e outra parte é própria;

c) do total da área da propriedade, $26,89 \%$ dos entrevistados afirmaram destinar entre 21 e $30 \%$ para o cultivo de trigo, $21,84 \%$ entre 41 e $50 \%$ e $13,44 \%$ entre 11 e $20 \%$;

d) o trigo assume o papel de cultura secundária nas propriedades, sendo que $94,96 \%$ dos entrevistados afirmaram ser a soja o principal produto cultivado em suas propriedades, enquanto que, para $48,74 \%$ dos entrevistados, o milho é a segunda principal cultura e, para 37,82\% dos produtores, o trigo é a segunda principal cultura da propriedade. Para $49,12 \%$, o trigo constitui-se no terceiro produto mais importante da propriedade;

e) todos os entrevistados afirmaram que a sua maior fonte de renda é proveniente da agricultura, no entanto, 101 deles $(84,8 \%)$ afirmaram que essa renda não é decorrente, em sua maior parte, da produção de trigo; 6 , ou $24,37 \%$ dos entrevistados, afirmaram que obtém renda bruta anual entre $R \$ 16.001,00$ e $R \$ 40.000,00$, enquanto 19,33\% deles obtêm renda anual entre $R \$ 80.001,00$ e $R \$ 160.000,00$.

No que concerne à comercialização agrícola do trigo pelos produtores rurais, ressalta-se que:

a) $47,06 \%$ dos entrevistados afirmaram ser o preço recebido pela saca de trigo a maior fonte de risco da atividade tritícola; 17,65\% declararam que as condições climáticas são o principal fator de risco da triticultura e $17,65 \%$ afirmaram ser a concorrência com o trigo importado;

b) $88,23 \%$ dos entrevistados afirmaram estar insatisfeitos com o retorno da atividade, pois, de fato, em muitos anos, o custo da lavoura suplantou o retorno;

c) 57 produtores ( $47,9 \%$ dos entrevistados) afirmaram utilizar algum tipo de contrato com cooperativas ou moinhos para fixar o preço de comercialização de parcela ou de toda a safra, mas $66,67 \%$ deles acreditam que esse contrato não tem sido efetivo em reduzir o risco de preços;

d) 53 dos produtores entrevistados $(44,54 \%)$ responderam possuir algum conhecimento de mercados futuros; destes, apenas 2 declararam ter conhecimento alto ou muito alto acerca do assunto; 
e) do total de entrevistados, 7 deles declararam utilizar algum contrato futuro disponível junto à BMËFBOVESPA, sendo que 5 deles utilizam o contrato de soja em grão e 2 utilizam os contratos de soja e milho;

f) $87,4 \%$ afirmaram estar dispostos a utilizar um novo instrumento de gerenciamento de risco de preço e $92,43 \%$ declararam ter interesse na adoção do contrato futuro de trigo.

Para a indústria moageira, reportam-se apenas alguns resultados em relação à comercialização do trigo em grão. Dos 10 moinhos entrevistados, 7 afirmaram ser a produção nacional a principal fonte de abastecimento de matéria-prima para moagem e 2 declararam ser a commodity importada da Argentina a sua principal fonte de matéria-prima. Em relação à principal fonte de risco associada à atividade da empresa, a concorrência estrangeira no suprimento de farinha de trigo à indústria de segundo processamento foi apontada por 4 entre os 10 moinhos respondentes, enquanto o preço pago pelo trigo foi apontado por 2 moinhos como o principal fator de risco de sua atividade empresarial.

Em relação à compra do trigo em grão, 8 moinhos afirmaram que são as cooperativas de produtores rurais o segmento por meio do qual eles realizam suas compras de matéria-prima, enquanto 1 moinho declarou comprar trigo diretamente de produtores rurais e 1 afirmou comprar, em maior parcela, de importadores.

Em 5 empresas entrevistadas, a comercialização do trigo é feita via contrato, e, em 3 empresas, parte da comercialização é feita por meio de contrato. Todas as empresas que afirmaram utilizar contrato responderam que o contrato tem como característica, em relação à definição do preço pago pela saca de trigo, que é definido por lote comprado, sendo que apenas 2 moinhos acreditam que o contrato tem sido efetivo na redução do risco de preço pago pela saca de trigo. Este é um fator favorável à implementação do contrato futuro de trigo no Brasil, pois tanto o segmento de produção quanto o de industrialização de trigo no Brasil sentem-se desprotegidos em relação ao risco de preço pelos contratos que utilizam.

Instados a responder sobre o conhecimento de mercados futuros, todos os gerentes de empresas entrevistados afirmaram ter algum conhecimento do funcionamento de mercados futuros. Porém, apenas 3 respondentes declararam ter conhecimento alto ou muito alto desses mercados e somente 2 entrevistados já utilizaram mercados futuros para se proteger de variações de preços, sendo que 1 utilizou o contrato da Bolsa de Chicago e da Bolsa de Kansas e o outro já utilizou tanto o contrato da Bolsa de Chicago quanto o contrato futuro de trigo da Bolsa de Buenos Aires.

Finalmente, convidados a responder se teriam interesse em utilizar o contrato futuro de trigo no Brasil, caso fosse lançado pela BMEFBOVESPA, 7 responderam que o utilizariam. Os 3 moinhos que responderam negativamente a essa per- 
gunta justificaram que os mercados futuros não se aplicam à moinhos de pequeno porte e, ainda, que é preferível trabalhar com o preço de mercado.

\section{Considerações Finais}

O mercado físico do trigo no país atende a grande parcela dos atributos considerados necessários para a implantação de um contrato futuro. Destaca-se a não existência de contratação a termo no mercado disponível do produto, a volatilidade acentuada dos preços, a possibilidade de armazenamento do cereal por um período relativamente longo, a estrutura do mercado - no qual não há integração vertical e o segmento de produção da commodity aproxima-se o máximo da concorrência perfeita - e o fato dos contratos já existentes em bolsas de mercadorias não serem efetivos na redução do risco de preços a que estão expostos os agentes da cadeia tritícola.

A volatilidade dos preços do trigo assemelha-se à volatilidade dos mercados físicos de soja e de milho, tanto nos estados do Paraná e Rio Grande do Sul, que respondem por $90 \%$ da produção nacional de trigo aproximadamente, quanto no estado de São Paulo, no qual está concentrada a maior parte das indústrias de moagem e de segundo processamento de trigo no país. Como o trigo encontra-se entre as commodities com volatilidade de preços mais elevada, torna-se patente $o$ risco de oscilações desfavoráveis de preços a que estão suscetíveis os agentes da cadeia e a necessidade de novos mecanismos de gerenciamento desse risco.

A análise do perfil dos potenciais usuários do contrato futuro de trigo mostrou-se mais um fator favorável ao lançamento desse contrato. Os produtores de trigo, em especial, constituem-se no segmento da cadeia tritícola mais interessado na adoção desse instrumento de gerenciamento de oscilações desfavoráveis de preços.

Acredita-se que esse percentual elevado de produtores interessados em adotar esse instrumento está ligado, principalmente, à insatisfação dos mesmos com o retorno da atividade. Os custos de produção do cultivo do trigo são bastante elevados e, nas últimas safras, têm sido superior à rentabilidade da lavoura. No entanto, cabe ressaltar que os entrevistados não participaram de nenhum tipo de treinamento sobre o funcionamento de mercados futuros e a maior parcela deles nunca atuou no mercado, tendo baixo nível de conhecimento a respeito. Entende-se, assim, que embora tenham respondido afirmativamente à intenção de adotar o contrato futuro de trigo, a resposta poderia ser diferente se os triticultores conhecessem os custos de se atuar nesse mercado, sobretudo para uma cultura que desempenha papel secundário na maioria das propriedades entrevistadas.

Por outro lado, pesam contra o lançamento desse contrato pela BMEFBOVESPA o tamanho do mercado físico, semelhante ao mercado do algo- 
dão, cujo contrato não teve êxito, e a intervenção governamental no setor, que gera distorções nos preços de mercado, de acordo com a política adotada.

O mercado à vista do cereal é considerado pequeno para dar liquidez ao contrato futuro de trigo. No entanto, o mercado consumidor do grão pode ser classificado como um mercado grande, de modo que o Brasil encontra-se em posição de destaque no ranking dos maiores produtores mundiais de biscoitos e massas alimentícias.

O principal fator desfavorável à implantação desse novo contrato refere-se às expectativas pouco positivas sobre aumentos expressivos na oferta do produto, decorrentes de produção doméstica. Com isso, a liquidez desse contrato estaria ameaçada, de modo que o lançamento do contrato futuro de trigo no Brasil é um movimento precipitado no mercado. Os incrementos de produção do cereal no país estão diretamente relacionados ao volume de financiamento concedido pelo governo federal para custeio da produção e às políticas de garantia de preços agrícolas.

Ressalta-se a dificuldade em se explorar o perfil das indústrias de moagem e de segundo processamento de trigo em relação à intenção de uso desse contrato, tendo em vista o baixo retorno dos questionários formulados e enviados a esses segmentos da cadeia e a impossibilidade de treinamento dos agentes da cadeia produtiva do trigo sobre o funcionamento de mercados futuros anteriormente ao preenchimento do questionário, o que fica como sugestão para trabalhos posteriores.

\section{Referências}

AGUIAR, D. R. D. Mercados futuros agropecuários. Viçosa, MG: Departamento de Economia Rural da UFV, 2003. Notas de aula.

ASSOCIAÇÃO BRASILEIRA DA INDÚSTRIA DO TRIGO. Associados. São Paulo, 2010. Disponível em: <http://www.abitrigo.com.br/index.php?mpg=03.00.00>. Acesso em: 31 jan. 2010.

BACHA, C. J. C. Economia e política agrícola no Brasil. 2. ed. São Paulo: Atlas, 2012.

BLACK, D. Success and failure of futures contracts: theory and empirical evidence. New York: Salomon Brothers Center for Study of Financial Institutions, 1986. (Monograph Series in Finance Economics, 1).

BRASIL. Ministério da Agricultura, Pecuária e Abastecimento. Regulamento técnico de identidade e de qualidade do trigo. Brasília, DF: Mapa, 2001. Disponível em: < http://sistemasweb. agricultura.gov.br/sislegis/action/detalhaAto.do?method=consultarLegislacaoFederal $>$. Acesso em: 25 jun. 2010.

. Ministério do Desenvolvimento, Indústria e Comércio Exterior. Sistema Aliceweb. Brasília, DF: MDIC, 2010. Disponível em: <http://aliceweb2.mdic.gov.br/>. Acesso em: 10 ago. 2010. 
BRORSEN, B. W.; FOFANA, N'ZUE F. Success and failure of agricultural futures contracts. Journal of Agribusiness, Atlanta, v. 28, n. 2, p. 129-145, 2001.

BRUM, A. L.; HECK, C. R. A economia do trigo no Rio Grande do Sul: breve histórico do cereal na economia do estado. Revista Análise, Porto Alegre, v. 16, n. 1, p. 29-44, 2005.

BRUM, A. L.; MÜLLER, P. K. A realidade da cadeia do trigo no Brasil: o elo produtores/cooperativas. Revista de Economia e Sociologia Rural, v. 46, n. 1, p. 145-169, 2008.

CAFÉ, S. L. et al. Cadeia produtiva do trigo. BNDES Setorial, Rio de Janeiro, n. 18, p. 193220, 2003.

CAPITANI, D. H. D.; REGAZZINI, L. C.; MATTOS, F. L. Viabilidade de implantação de um contrato futuro de arroz no Brasil: uma análise dos pré-requisitos necessários. In: CONGRESSO DA SOCIEDADE BRASILEIRA DE ECONOMIA, ADMINISTRAÇÃO E SOCIOLOGIA RURAL, 48., 2010, Campo Grande. Anais... Brasília, DF: Sober, 2010.

CLEMENTE, F. Viabilidade de implantação de contratos futuros de suco de laranja concentrado congelado no Brasil. 2010. 109 f. Monografia (Bacharelado em Ciências Econômicas) - Universidade Federal de Viçosa, Viçosa, MG, 2010.

COLLE, C. A. A cadeia produtiva do trigo no Brasil: contribuição para a geração de emprego e renda. 1998. 160 f. Dissertação (Mestrado em Economia Rural) - Universidade Federal de Rio Grande do Sul, Porto Alegre, 1998.

COMPANHIA NACIONAL DE ABASTECIMENTO. Brasil: balanço de oferta e demanda. Brasília, DF, 2010. Disponível em: <http://www.conab.gov.br/conteudos.php?a $=548 \mathcal{E} \mathrm{t}=2 \#-$ this >. Acesso em: 28 fev. 2010.

COSTA, A. A. Condições para implantação do contrato futuro de arroz no Brasil. 2008. $134 \mathrm{f}$. Dissertação (Mestrado em Economia Aplicada) - Universidade Federal de Viçosa, Viçosa, MG, 2008.

EMPRESA BRASILEIRA DE PESQUISA AGROPECUÁRIA. Culturas: trigo. Passo Fundo: Embrapa, 2010.

GIL, A. C. Métodos e técnicas de pesquisa social. 5. ed. São Paulo, Atlas, 1999.

GOMES, M. T. M. Potencialidades de inserção do carvão vegetal em bolsa de mercadorias. 2006. 88 f. Dissertação (Mestrado em Ciência Florestal) - Universidade Federal de Viçosa, Viçosa, MG, 2006.

HULL, J. C. Fundamentos dos mercados futuros e de opções. 4. ed. São

Paulo: Bolsa de Mercadorias e Futuros, 2005.

INSTITUTO BRASILEIRO DE GEOGRAFIA E ESTATÍSTICA. Sistema IBGE de Recuperação Automática (SIDRA). Tabelas 1612 e 1613. Brasília: 2010. Disponível em: < http://www.sidra. ibge.gov.br/>. Acesso em: 20 set. 2010.

Censo agropecuário 2006. Brasília, 2010. Disponível em: <http://www.ibge.gov.br/ home/estatistica/economia/agropecuaria/censoagro/> . Acesso em: 21 maio 2010.

. Censo agropecuário de 1995-1996. Brasília, 2010. Disponível em: <http://www.ibge. gov.br/home/estatistica/economia/agropecuaria/censoagro/1995_1996/default.shtm > . Acesso em: 21 maio 2010.

LEISMANN, E. L. Retornos e riscos na comercialização de milho no estado do Paraná: uma aplicação do modelo value-at-risk. 2002. 177 f. Tese (Doutorado em Economia Aplicada) Universidade Federal de Viçosa, Viçosa, MG, 2002. 
MÜLLER, C. A. S. Análise da efetividade das estratégias estáticas e dinâmicas de hedge para o mercado brasileiro de café arábica. 2007. Tese (Doutorado em Economia Aplicada) - Universidade Federal de Viçosa, Viçosa, MG, 2007.

PENNINGS, J. M. E.; LEUTHOLD, R. M. Commodity futures contract viability: a multidisciplinary approach. Urbana-Champaign: University of Illinois, 1999. (OFOR Paper).

PURCELL, W. D.; KOONTZ, S. R. Agricultural futures and options principles and strategies. 2. ed. Upper Saddle River: Prentice Hall, 1999.

ROSSI, R. M.; NEVES, M. F. (Coord.). Estratégias para o trigo no Brasil. São Paulo: Atlas, 2004.

SANTOS, A. H. G. Viabilidade de implantação do contrato futuro de suínos no Brasil. 2001. 110 f. Dissertação (Mestrado em Economia Aplicada) - Universidade Federal de Viçosa, Viçosa, MG, 2001.

SANTOS, A. H. G.; AGUIAR, D. R. D. Análise dos fatores determinantes da viabilidade de implantação do contrato futuro de suínos vivos no Brasil. Revista de Economia e Agronegócio, Viçosa, v. 1, n. 2, p. 231-256, 2003.

SCHWANTES, F. Viabilidade da implantação do contrato futuro de trigo na BMEFBOVESPA. 2010. 154 f. Dissertação (Mestrado em Economia Aplicada) - Universidade Federal de Viçosa, Viçosa, MG, 2010.

SIQUEIRA, K. B. Avaliação da viabilidade de contratos futuros de leite no Brasil. 2003. Dissertação (Mestrado em Economia Aplicada) - Universidade Federal de Viçosa, Viçosa, MG, 2003.

SOARES, N. S. Potencial de implantação de um contrato futuro da madeira de reflorestamento. 2006. 120 f. Dissertação (Mestrado em Ciência Florestal) - Universidade Federal de Viçosa, Viçosa, MG, 2006.

SOUZA, W. A. Determinantes da viabilidade de mercados futuros agropecuários no âmbito do Mercosul. 1998. Tese (Doutorado em Economia Aplicada) - Escola Superior de Agricultura Luiz de Queiroz, Universidade de São Paulo, Piracicaba, SP, 1998.

UNITED STATES OF AMERICA. Department of Agriculture. Downloadable Data Sets. Washington, DC, 2010. Disponivel em: < http://www.fas.usda.gov/psdonline/download/psd grains_pulses_csv.zip $>$. Acesso em: 31 jun. 2010.

Recebido em: 28/06/2012

Aceito em: 25/01/2013. 